See discussions, stats, and author profiles for this publication at: https://www.researchgate.net/publication/326837590

\title{
Investigation on Silent Bacterial Infections in Specimens from Pregnant Women Affected by Spontaneous Miscarriage.
}

Article in Journal of Cellular Physiology · August 2018

DOI: $10.1002 /$ jcp. 26952

CITATIONS

0

11 authors, including:

Carlo Contini

University of Ferrara

210 PUBLICATIONS 1,042 CITATIONS

SEE PROFILE

S1. Silva Seraceni

IRCCS Ospedale Infantile Burlo Garofolo

71 PUBLICATIONS 644 CITATIONS

SEE PROFILE

Some of the authors of this publication are also working on these related projects:

The role of Chlamydia in Ocular Lymphoma View project

Project Silent Intracellular Infections during Pregnancy View project
46

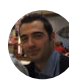

John Charles Rotondo

18 PUBLICATIONS 77 CITATIONS

SEE PROFILE

Martina Maritat

University of Ferrara

42 PUBLICATIONS 14 CITATIONS

SEE PROFILE 


\title{
Investigation on silent bacterial infections in specimens from pregnant women affected by spontaneous miscarriage
}

\author{
Carlo Contini $^{1 *}$ | John C. Rotondo ${ }^{2 *}$ | Federica Magagnoli ${ }^{2}$ | Martina Maritati ${ }^{1}$ | \\ Silva Seraceni $^{1}$ | Angela Graziano ${ }^{3}$ | Alice Poggi $^{3}$ | Roberta Capucci ${ }^{3}$ | \\ ${\text { Fortunato } \text { Vesce }^{3} \text { | Mauro Tognon }}^{2}$ (i) | Fernanda Martini ${ }^{2}$
}

${ }^{1}$ Department of Medical Sciences, Section of Infectious Diseases and Dermatology, University of Ferrara, Ferrara, Italy

${ }^{2}$ Department of Morphology, Surgery and Experimental Medicine, Section of Pathology, Oncology and Experimental Biology, University of Ferrara, Ferrara, Italy

${ }^{3}$ Department of Morphology, Surgery and Experimental Medicine, Section of Obstetrics and Gynecology, Ferrara, Italy

\section{Correspondence}

Fernanda Martini, Department of Morphology, Surgery and Experimental Medicine, University of Ferrara, 64/B, Fossato di Mortara Street, Ferrara 44121, Italy. Email: mrf@unife.it

\section{Funding information}

Ministero della Salute, Grant/Award Number: Ricerca finalizzata Young Investigators 2015; Università degli Studi di Ferrara, Grant/Award Numbers: FAR grants 2016, 2017, 2015, 2018
Miscarriage is one of the main complications occurring in pregnancy. The association between adverse pregnancy outcomes and silent bacterial infections has been poorly investigated. Ureaplasma parvum and urealiticum, Mycoplasma genitalium and hominis and Chlamydia trachomatis DNA sequences have been investigated by polymerase chain reaction (PCR) methods in chorionic villi tissues and peripheral blood mononuclear cells (PBMCs) from females with spontaneous abortion (SA, $n=100$ ) and females who underwent voluntary interruption of pregnancy (VI, $n=100$ ). U. parvum DNA was detected in $14 \%$ and $15 \%$ of SA and VI, respectively, with a mean of bacterial DNA load of $1.3 \times 10^{-1}$ copy/cell in SA and $2.8 \times 10^{-3}$ copy/cell in VI; $U$. urealiticum DNA was detected in $3 \%$ and $2 \%$ of SA and VI specimens, respectively, with a mean DNA load of $3.3 \times 10^{-3}$ copy/cell in SA and $1.6 \times 10^{-3}$ copy/cell in VI; M. hominis DNA was detected in $5 \%$ of SA specimens with a DNA load of $1.3 \times 10^{-4}$ copy/cell and in $6 \%$ of $\mathrm{VI}$ specimens with a DNA load of $1.4 \times 10^{-4}$ copy/cell; C. trachomatis DNA was detected in $3 \%$ of SA specimens with a DNA load of $1.5 \times 10^{-4}$ copy/cell and in $4 \%$ of VI specimens with a mean DNA load of $1.4 \times 10^{-4}$ copy/cell. In PBMCs from the SA and VI groups, Ureaplasma spp, Mycoplasma spp and C. trachomatis DNAs were detected with a prevalence of $1 \%-3 \%$. Bacteria were investigated, for the first time, by quantitative real-time PCR (qPCR) in chorionic villi tissues and PBMCs from women affected by SA and VI. These data may help to understand the role and our knowledge of the silent infections in SA.

\section{KEYWORDS}

bacterial infections, Chlamydia trachomatis, Mycoplasma genitalium, Mycoplasma hominis, pregnancy, silent infections, spontaneous abortion (SA), spontaneous miscarriage, Ureaplasma parvum, Ureaplasma urealiticum

\section{1 | INTRODUCTION}

Miscarriage is one of the main complications during pregnancy, which occurs in approximately $15 \%-20 \%$ of pregnancies. It has been reported that nearly $70 \%$ of early miscarriages occur during the first

*Contini and Rotondo contributed equally to this work. trimester, whereas $30 \%$ of late miscarriages are registered between the 13th and the 22nd week (Cardenas et al., 2010; Giakoumelou et al., 2016). There are many diferent causes of miscarriage, including iatrogenic agents, which are yet to be identified. Among the wellestablished causes, there are chromosomal abnormalities (Suzumori \& Sugiura-Ogasawara, 2010), age of parents (de la Rochebrochard \& Thonneau, 2002; Maconochie, Doyle, Prior, \& Simmons, 2007), 
uterine, immune system and/or hormonal abnormalities (Cardenas et al., 2010; Mor \& Cardenas, 2010), tissue rejection, and reproductive tract infections (Cardenas et al., 2010; Nigro et al., 2011), as well as male factors (Absalan et al., 2012; Rotondo et al., 2012). Male factors account for $10 \%-15 \%$ of early miscarriages, while up to $66 \%$ of late miscarriages (Giakoumelou et al., 2016; Nigro et al., 2011).

The association between adverse pregnancy outcomes and infections of the host has been poorly investigated, while intrauterine infections occurring in early and late pregnancy periods, leading to spontaneous abortion (SA) and spontaneous preterm birth, have been reported (Donders et al., 2000; Robertson, 1986).

In recent years, many studies have been carried out on amniotic fluids, investigating samples by bacterial cultures and/or by polymerase chain reaction (PCR) techniques. These investigations reported the isolation/identification of different bacteria such as: (a) Ureaplasma spp, which are the most frequently isolated microorganisms inside the amniotic cavity during pregnancy; these bacteria have been associated with SA, intra-amniotic infection, named chorioamnionitis, premature rupture of the membranes (PROM), and preterm labor (Yoon et al., 1998); (b) Ureaplasma urealyticum or Mycoplasma hominis in midtrimester amniotic fluids showed to be per se a risk factor for subsequent PROM (Perni et al., 2004); (c) Ureaplasma parvum Biovar 1, which is a group of bacterial strains that differ physiologically/biochemically from other strains in the same species, and is correlated in amniotic fluid with an increased intrauterine inflammatory response and elevated interleukin 8 levels (Miles et al., 2009; Novy et al., 2009); (d) Chlamydia trachomatis, which is diagnosed as the most common sexually transmitted bacterial infection worldwide and has been found to be associated with female infertility (Ahmadi et al., 2016; Baud et al., 2011). In pregnant women, $C$. trachomatis is considered a causative agent of SA because it stimulates the intrauterine inflammatory response or leads to excessive maternal immunogenic reaction to embryonic antigens (Adachi, Nielsen-Saines, \& Klausner, 2016; Nigro et al., 2011). Yet, the effects of $C$. trachomatis, as well as other pathogens constituting the toxoplasmosis, rubella, cytomegalovirus and herpes simplex (ToRCH) complex, in determining abortion remain controversial (Giakoumelou et al., 2016), as little information is available about the impact of ToRCH coinfections on the outcome of pregnancy (Rasti et al., 2016).

Most of the studies have been carried out on amniotic fluids from women with premature birth by bacterial cultures. It has been speculated that a higher percentage of amniotic fluid samples may carry bacteria, but these infections could be undetectable because of the limitations of standard culture techniques (Giakoumelou et al., 2016; Yoon et al., 2000). More recently, PCR techniques have been used for identification of many microorganisms in amniotic fluids, providing a higher detection rate of pathogens that may escape detection by cultivation techniques. PCR analyses were useful to identify infections in patients with preterm labor and intact membranes, as well as preterm delivery and intra-amniotic infection compared with standard microbial cultures (Oyarzún et al., 1998; Romero et al., 2015). The use of molecular techniques likely increases the detection of infections among patients with obstetric complications (Yoon et al., 2000). However, the clinical significance of a positive PCR assay of amniotic fluids for specific microorganisms has not been determined, whereas conventional PCR is restricted in the accurate quantification of microorganisms. In this setting, the use of molecular methods, including quantitative real-time PCR (qPCR), although useful for the simultaneous detection and Biovar discrimination of U. urealyticum in clinical specimens (Yi, Yoon, \& Kim, 2005), has not been extensively used to search bacterial DNA in pregnant women with SA. In addition, there is little evidence on the search for bacterial pathogens within trophoblasts, the cells of the chorionic villi, which are critical for anchoring the embryo to the maternal tissue. Yet, exchanges of all nutrients and waste materials, which occur through its cells, play a significant role in the pregnancy physiology. Indeed, the damage of the trophoblastic layer by an infectious agent could result in abnormal placentation or expulsion of the embryo, causing abortion (You et al., 2008).

In this study, the association between some silent bacterial infections and early SA was investigated. For this purpose, PCR techniques were used to analyze DNAs from chorionic villi. Specimens were from aborted tissues collected from women with SA (the cases) and women undergoing voluntary pregnancy interruption (VI) (the control group). In addition, the same bacterial DNA targets were searched in peripheral blood mononuclear cells (PBMCs) from women with SA and VI.

\section{2 | MATERIALS AND METHODS}

\section{1 | Specimens}

Chorionic villi tissue specimens $(n=200)$ and corresponding PBMCs $(n=200)$ were collected from pregnant women. A written informed consent was obtained from all women. The Ethics Committee of Ferrara approved the study. Specimens were obtained from two different cohorts: females with SA $(n=100)$, the cases; and females who underwent VI $(n=100)$, the controls. The mean ages ( \pm standard deviation) of SA and VI cohorts were $36 \pm 6$ and $32 \pm 7$ years, respectively. The two cohorts had a gestational age $\leq 12$ weeks. The number of pregnancies was similar for both groups, between 1 and 6 .

\subsection{DNA isolation}

DNA isolation and purification from chorionic villi were carried out as previously reported (Kooper et al., 2009). Briefly, $25 \mathrm{mg}$ of chorionic tissue was incubated with proteinase $\mathrm{K}, \mathrm{ON}$ at $56^{\circ} \mathrm{C}$. Then, DNA was extracted using a QIAmp DNA Blood and Tissue Extraction Kit (Qiagen, Milan, Italy; Rotondo et al., 2016). Total DNA from PBMCs was isolated using a QIAmp DNA Mini Extraction Kit (Qiagen) (Rotondo, Bononi et al., 2017). After DNA extraction, each sample was quantified and evaluated for its PCR suitability by spectrophotometric reading (NanoDrop 2000, Thermo Fisher Scientific, Monza, Italy) and by amplifying the $\beta$-globin gene sequence, 
respectively (Rotondo et al., 2015). DNA was stored at $-80^{\circ} \mathrm{C}$ until the time of the analysis.

\section{3 | Bacterial DNA detection}

In the first phase of our analysis, the presence of bacterial DNA in SA and VI chorionic villi and PBMCs was assessed using two different qualitative techniques. Specifically, genomic DNA sequences belonging to Ureaplasma spp and Mycoplasma spp were investigated using hemi-nested PCR (hn-PCR) and PCR, respectively (Cultrera, Seraceni, Germani, \& Contini, 2006). The genomic DNA sequence of $C$. trachomatis was investigated by nested-PCR (Borghi et al., 2013). In PCR techniques, the following primers sets were used: (a) UU3/UU4 and UU5, targeting the urease gene of the most common human Ureaplasmas (Cultrera et al., 2006); (b) MGSO/ RNA5 and MGSO/GPO1 primer sets, targeting the $16 \mathrm{~S}$ gene region of the most common human Mycoplasmas (a true positivity was considered if obtained with both pairs of primers; Cultrera et al., 2006); (c) and $16 \mathrm{~S}$ generis, 16s-chtracho primer sets, targeting the 165 gene region of C. trachomatis (Borghi et al., 2013).

\section{4 | Mycoplasma spp DNA sequencing}

To verify the presence of human mycoplasma DNA sequences in SA and VI chorionic villi, Micoplasma spp-DNA-positive MGSO/GPO1 amplicons were subjected to direct DNA sequence analysis. Specifically, SA $(n=5)$ and VI $(n=6)$ samples, MGSO/GPO1 amplicons (717 nt of the human Micoplasma spp 16s gene) were purified using the QIAquick PCR Purification Kit (Qiagen; Rotondo et al., 2013). Amplicons were subsequently sequenced with automated ABIPrism3730xI Genetic-Analyser (Applied Biosystems, Monza, Italy; Rotondo, Candian et al., 2017). The resulting bacterial DNA sequences were BLAST versus the human $M$. hominis (GenBank, accession no. NC_013511.1) and genitalium (GenBank, accession no. NC_000908.2) DNA strains present in the National Center for Biotechnology Information (NCBI) database (http://www.ncbi.nlm.nih.gov/blast/Blast.cgi).

\section{5 | Bacterial DNA load quantification}

In the second phase of our analysis, genomic DNA sequences from Ureaplasma spp, Mycoplasma spp and C. trachomatis, detected by qualitative PCR analyses in SA and VI chorionic villi, were quantified in bacterial DNA-positive samples by qPCR (RealLine, Bioron Diagnostics GmbH, Ludwigshafen, Germany). The GyrA and ORF1 (in cryptic plasmid) genes of $C$. trachomatis, including a Swedish variant and the serotypes A-C, the GAP gene of Mycoplasma genitalis and hominis, and the ureC gene of $U$. parvum and urealyticum, respectively, were detected. Amplification/detection of PCR products was performed with the CFX96 Deep WellTM (Bio-Rad, Segrate, Italy). Samples and controls were analyzed in duplicate by two different operators. Bacterial DNA loads were reported as bacterial DNA copy/cell. The detection limit of the assay was two copies/cell for each pathogen. Negative controls containing $\mathrm{H}_{2} \mathrm{O}$, void of DNA template, were included in each qPCR batch.

\subsection{Statistical analysis}

The prevalence of bacterial DNAs in SA and VI chorionic tissues and PBMCs was statistically analysed using the chi-square trend test.

(a)

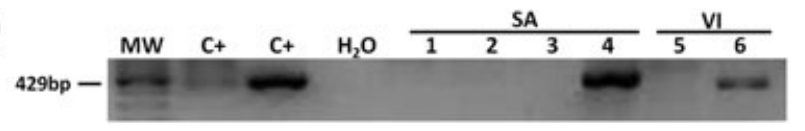

(b)
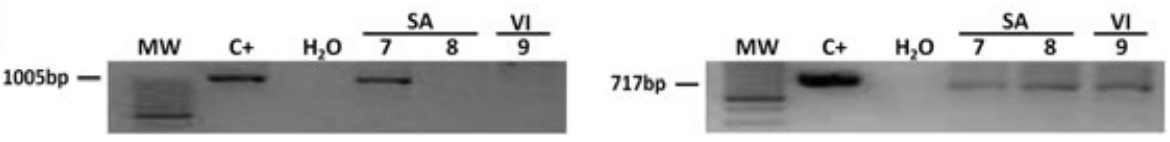

(c)

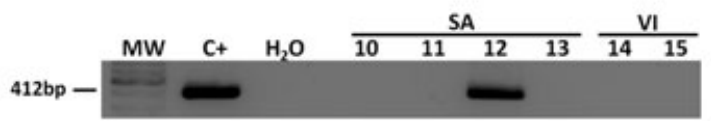

FIGURE 1 Bacterial DNA in SA and VI chorionic villi. Agarose gel electrophoresis of hn-PCR/PCR products stained by ethidium bromide and visualized by UV. MW: molecular weight. $\mathrm{C}+$ : positive controls. $\mathrm{H}_{2} \mathrm{O}$ : negative controls of hn-PCR/PCR reactions without DNA template. The arrow indicates hn-PCR/PCR product sizes. (a) Representative UU4 and UU5 hn-PCR-amplified Ureaplasma spp urease gene sequences. Lanes 1-4 and 5-6, DNA samples extracted from SA and VI chorionic villi, respectively. (b) On the left, representative MGSO and RNA5 PCR-amplified Mycoplasma spp $16 \mathrm{~S}$ gene sequences. Lanes 7-8, and 9, DNA samples extracted from SA and VI chorionic villi, respectively. On the right, representative MGSO and GPO1 PCR-amplified Mycoplasma spp 16S gene sequences. Lanes 7-8 and 9, DNA samples extracted from SA and VI chorionic villi, respectively. A true positive sample was considered when tested positive by both PCRs, for example, line seven of both gels. (c) Representative 16S generis, 16s chtracho PCR-amplified Chlamydia trachomatis 165 gene sequences. Lanes 10-13 and 14-15, DNA samples extracted from SA and VI chorionic villi, respectively. hn-PCR: hemi-nested polymerase chain reaction; SA: spontaneous abortion; VI: voluntary interruption 
A paired $t$ test was used to compare the bacterial DNA load means. All statistical analyses were carried out using Graph Pad Prism version 5.0 for Windows (Graph Pad, La Jolla, CA). p-values $<0.05$ were considered statistically significant.

\section{3 | RESULTS}

\section{1 | Ureaplasma parvum and Ureaplasma urealiticum DNAs}

Ureaplasma spp DNA was detected by qualitative hn-PCR in 17 out of 100 DNAs (17\%) from SA and VI chorionic tissue specimens (Figure 1a). These DNAs investigated by qPCR allowed us to detect U. parvum DNA in 14\% (14/100) and 15\% (15/100) of SA and VI, respectively (Table 1; $p>0.05$ ). Furthermore, bacterial DNA sequences belonging to $U$. urealiticum were detected in $3 \%(3 / 100)$ and $2 \%$ $(2 / 100)$ of SA of VI samples, respectively (Table $1 ; p>0.05)$. In the SA group, the $U$. parvum DNA-positive samples were statistically higher compared to $U$. urealiticum DNA-positive samples $(p=0.0053)$. In the VI group, $U$. parvum DNA-positive samples were statistically higher compared with $U$. urealiticum $(p=0.0010)$. None of the samples tested positive for both $U$. parvum and $U$. urealiticum bacteria.

In PBMCs, Ureaplasma spp DNA, analyzed by qualitative hn-PCR, was revealed in $2 \%(2 / 100)$ of samples from the SA group, whereas the DNA belonging to this pathogen was detected in $1 \%(1 / 100)$ of samples from the VI group (Table 2). The difference between the SA and VI groups was not statistically significant $(p>0.05)$.

\subsection{Mycoplasma genitalium and Mycoplasma hominis DNAs}

In chorionic tissue specimens, Mycoplasma spp DNA was detected by qualitative PCR in 5\% (5/100) of the SA samples and in 6\% (6/100) of the VI samples (Figure 1b). The different prevalence between the two SA and VI samples was not statistically significant $(p>0.05)$. QPCR confirmed our qualitative data indicating that the Mycoplasma sppDNA positive samples were all positive for $M$. hominis (Table 1 ). Indeed, the DNA sequences of $M$. genitalium were absent in both SA and $\mathrm{VI}$ cohorts. The prevalence of positive $M$. hominis DNAs in SA samples was statistically significant compared with $M$. genitalium $(p=0.0235)$. Similarly, the prevalence of positive $M$. hominis DNAs in VI samples was statistically significant compared with $M$. genitalium
TABLE 2 Prevalence of DNA sequences of Ureaplasma spp, Mycoplasma spp, and Chlamydia trachomatis in PBMC samples

\begin{tabular}{llll} 
& \multicolumn{3}{l}{ Number of positive samples/samples analyzed (\%) } \\
\cline { 2 - 4 } $\begin{array}{l}\text { Tissue } \\
\text { sample }\end{array}$ & $\begin{array}{l}\text { Ureaplasma } \\
\text { spp }\end{array}$ & $\begin{array}{l}\text { Mycoplasma } \\
\text { spp }\end{array}$ & $\begin{array}{l}\text { Chlamydia } \\
\text { trachomatis }\end{array}$ \\
\hline SA & $2 / 100(2)$ & $3 / 100(3)$ & $0 / 100(0)$ \\
VI & $1 / 100(1)$ & $3 / 100(3)$ & $1 / 100(1)$ \\
$p$ value & 1.0000 & 1.0000 & 1.0000 \\
\hline
\end{tabular}

SA: spontaneous abortion; VI: voluntary interruption

( $p=0.0129)$. Furthermore, one VI sample tested co-infected with both $M$. hominis and $U$. parvum.

In PBMCs, DNA belonging to Mycoplasma spp was detected in 3\% $(3 / 100)$ of SA and VI samples (Table $2 ; p>0.05$ ).

\section{3 | Chlamydia trachomatis DNA}

The genomic DNA sequences of $C$. trachomatis were detected by qualitative nested-PCR in $3 \%(3 / 100)$ and $4 \%(4 / 100)$ of SA and VI chorionic tissue specimens, respectively (Figure 1c). The difference between the two groups was not statistically significant $(p>0.05$; Table 1). These results were confirmed by subsequent qPCR. Furthermore, we detected that one $\mathrm{VI}$ and one SA sample were coinfected with $C$. trachomatis and $U$. parvum, and $C$. trachomatis and $M$. hominis, respectively. In the PBMCs from the SA group, C. trachomatis DNAs was not detected, whereas $1 \%(1 / 100)$ of samples belonging to the $\mathrm{VI}$ group tested DNA-positive for this bacterium (Table $2 ; p>0.05$ ).

\section{4 | Bacterial DNA load quantification}

The bacterial DNA load from chorionic tissues was evaluated by qPCR (Figure 2). Ureaplasma spp, Mycoplasma spp and C. trachomatis DNAs, detected by qualitative PCR assays, were confirmed by qPCR.

In quantitative PCR assays, the mean $U$. urealiticum DNA load was $3.3 \times 10^{-3}$ copy/cell (range $7.3 \times 10^{-4}-7.6 \times 10^{-3}$ copy/cell) in the SA group $(n=3)$ and $1.6 \times 10^{-3}$ copy/cell (range $2.2 \times 10^{-4}-3 \times 10^{-3}$ copy/cell) in the VI group $(n=2)$. The difference in DNA loads between the groups was not statistically significant $(p>0.05$;

TABLE 1 Prevalence of DNA sequences of Ureaplasma parvum, Ureaplasma urealiticum, Mycoplasma genitalium, Mycoplasma hominis and Chlamydia trachomatis in chorionic villi samples

\begin{tabular}{|c|c|c|c|c|c|}
\hline \multirow[b]{2}{*}{ Tissue sample } & \multicolumn{5}{|c|}{ Number of positive samples/samples analyzed (\%) } \\
\hline & Ureaplasma parvum & Ureaplasma urealiticum & Mycoplasma genitalium & Mycoplasma hominis & Chlamydia trachomatis \\
\hline SA & $14 / 100(14)$ & $3 / 100(3)$ & $0 / 100(0)$ & $5 / 100(5)$ & $3 / 100(3)$ \\
\hline VI & $15 / 100(15)$ & $2 / 100(2)$ & $0 / 100(0)$ & $6 / 100(6)$ & $4 / 100(4)$ \\
\hline$p$ value & 0.8404 & 0.6506 & 1.000 & 0.7564 & 0.7004 \\
\hline
\end{tabular}

SA: spontaneous abortion; VI: voluntary interruption. 
(a)

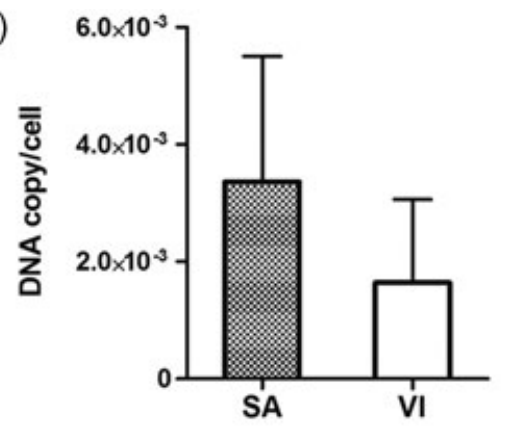

FIGURE 2 Bacterial DNA load distribution in chorionic villi. Mean bacterial DNA load (bacterial DNA copy/cell) of (a) Ureaplasma urealiticum in SA $(n=3)$ and VI $(n=2)$ groups; (b) Ureaplasma parvum in SA $(n=14)$ and VI $(n=15)$ groups; (c) Mycoplasma hominis in SA $(n=5)$ and VI $(n=6)$ groups; (d) Chlamydia trachomatis in SA $(n=3)$, VI $(n=4)$ groups. Error bars represent standard error of mean. SA: spontaneous abortion; VI: voluntary interruption

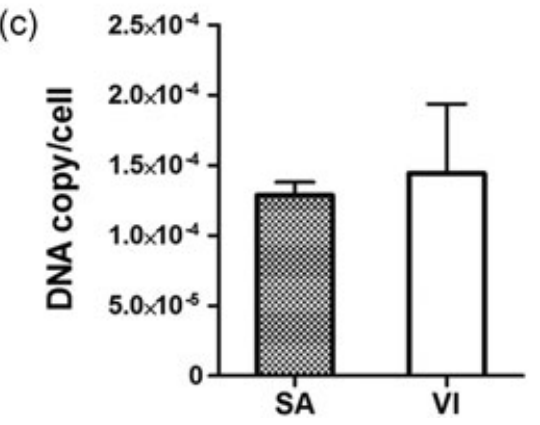

(b)

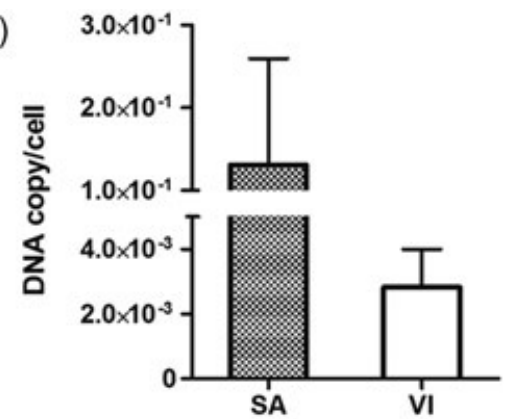

(d)

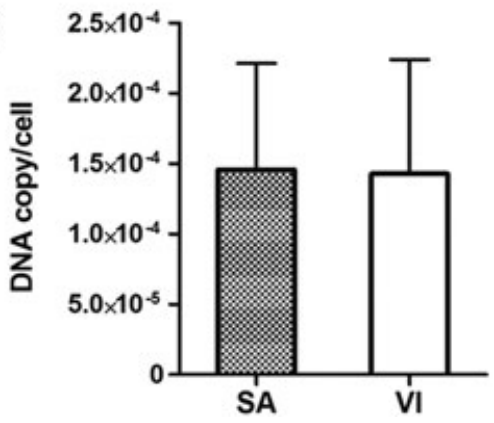

Figure 2a). The mean U. parvum DNA load was $1.3 \times 10^{-1}$ copy/cell (range $5.5 \times 10^{-5}-1.7 \times 10^{-1}$ copy/cell) in the SA group $(n=14)$ and $2.8 \times 10^{-3} \mathrm{copy} /$ cell (range $1.9 \times 10^{-4}-1.4 \times 10^{-2}$ copy/cell) in the VI group $(n=15)$. The difference in DNA loads between the groups was not statistically significant ( $p>0.05$; Figure $2 b$ ). The mean $M$. hominis DNA load was $1.3 \times 10^{-4}$ copy/cell (range $1.1 \times 10^{-4}-1.6 \times 10^{-4}$ copy/cell) in the SA group $(n=5)$ and $1.4 \times 10^{-4}$ copy/cell (range $5.5 \times 10^{-5}-3.6 \times 10^{-4}$ copy/cell) in the VI group $(n=6)$. The difference in DNA loads between the groups was not statistically significant ( $p>0.05$; Figure $2 c)$. In chorionic villi from the SA group $(n=3)$ a mean $C$. trachomatis DNA load of $1.5 \times 10^{-4}$ copy/cell (range $5.3 \times 10^{-5}-3 \times 10^{-4}$ copy/cell) was detected, whereas in specimens from the VI group $(n=4)$, a mean DNA load of $1.4 \times 10^{-4}$ copy/cell (range $5.8 \times 10^{-5}-3.6 \times 10^{-4}$ copy/cell) was detected. The difference in DNA loads between groups was not statistically significant $(p>0.05$; Figure $2 \mathrm{~d})$.

\section{5 | Mycoplasma spp DNA sequence analysis}

Eleven Mycoplasma spp-DNA positive chorionic tissue specimens, $n=5$ and $n=6$ samples from SA and VI groups, respectively, were subjected to DNA sequence analysis. Mycoplasma spp DNA sequence analysis confirmed our results obtained by qualitative and quantitative assays. Specifically, sequences were $100 \%$ concordant with

(a)

Reference:

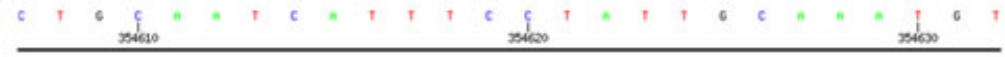

(b)

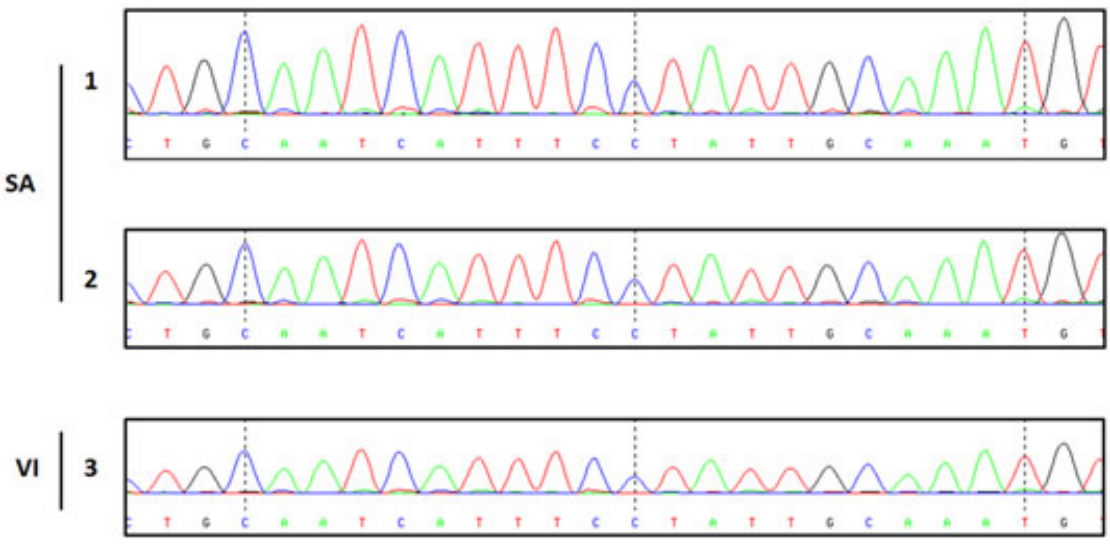

FIGURE 3 Mycoplasma spp DNA sequence analysis. (a) Reference, Mycoplasma hominis (GenBank, accession no. NC_013511.1) partial 16s gene strain. (b) Three representative Partials MGSO and GPO1 sequences of three Mycoplasma hominis-DNA positive samples belonging to SA (samples 1 and 2) and VI (sample 3) groups. M. hominis was the unique strain detected in Mycoplasma-DNA positive chorionic tissues. SA: spontaneous abortion; VI: voluntary interruption [Color figure can be viewed at wileyonlinelibrary.com] 
M. hominis (GenBank, accession no. NC_013511.1) in all Mycoplasma spp-DNA positive chorionic tissues (Figure 3).

\section{4 | DISCUSSION}

Miscarriage can be a main complication of pregnancy, the prevalence of which accounts for $15 \%-20 \%$ of all pregnancies. The different causes of the miscarriage are not completely understood. Silent bacterial infections were associated with early and late pregnancy loss and the dynamics of infection are actively investigated by different researchers. SA accounts, as possible bacterial inductive factors, for the Ureaplasma, Mycoplasma and C. trachomatis infections of the female genital tract (Ahmadi et al., 2014; Baud et al., 2011; Larsen \& Hwang, 2010).

Ureaplasma parvum DNA was detected in both, women affected by early pregnancy loss and control women, confirming that this pathogen is fairly distributed in the female genital tract (TaylorRobinson, 2017). Moreover, we observed a high bacterial DNA load within women affected by miscarriage (SA) in comparison with the control group (VI). So far, the $U$. parvum DNA load was not investigated before in chorionic villi among women affected by early pregnancy loss. Previously, the presence of this pathogen was evaluated in amniotic fluids and associated with miscarriage (Romero et al., 1989). Our data, together with previous reports, may indicate that this pathogenic bacterium probably is involved in the early pregnancy loss. However, the role of this pathogen in the onset of this phenomenon needs further investigations. The prevalence of $U$. urealiticum in the chorionic villi specimens from both women affected by early pregnancy loss and controls resulted lower to that of $U$. parvum. These results may suggest that this pathogen could infect other anatomic districts of the female genital tract, such as the uterine cervix. In fact, DNA sequences of this pathogen have previously been observed in the uterine endo-cervix and associated with SA (Ahmadi et al., 2014). The prevalence of Ureaplasma DNA, seldom detected in PBMCs of SA and VI cohorts, is in agreement with the low prevalence of these sequences in the chorionic villi specimens. Very likely, the Ureaplasma infection does not play a pathogenic role in these women.

Considering a putative association between Mycoplasma infection and early pregnancy loss (Larsen \& Hwang, 2010), we investigated the presence of this pathogen in chorionic villi and PBMCs from cases and control. M. hominis DNA was detected at low prevalence in chorionic villi from both SA and VI cohorts. In addition, the bacterial DNA load was similar in the two groups. To the best of our knowledge, although $M$. hominis has been previously studied in the placenta (Cardenas et al., 2010) and in the uterine tract (Farhadifar et al., 2016) of both women affected by miscarriage and pregnant women, the investigation of this pathogen in chorionic villi from aborted material was reported only in a single study (Donders et al., 2000). Our data, together with previous reports, may indicate that this pathogen could not infect the chorionic villi as natural infection site and, in turn, could not be involved to the loss of the embryo.
In the current study, we investigated, for the first time, the presence of $M$. genitalium DNA in chorionic villi belonging to women affected by miscarriage and a control group. M. genitalium DNA was not revealed. M. genitalium infections do not appear to affect pregnancy outcome, as previously reported (Giakoumelou et al., 2016). The PBMC analysis of generic Mycoplasma spp confirmed our investigation conducted in chorionic villi, indicating low positivity for this pathogen. These data confirm that the majority of women enrolled in this study have no active Mycoplasma infection.

In the current study, we observed a low C. trachomatis DNA positivity in the chorionic villi from women affected by SA. In addition, in our study group, we observed a DNA-positivity for this pathogen similar to that observed in the control group. Accordingly, this study reports, for the first time, a similar bacterial DNA load in chorionic villi in women affected by miscarriage and in the control group. Previously, DNA belonging to this bacterium was detected in chorionic villi from pregnant women with a low frequency (Dong, Li, Zhang, \& Liu, 1998). Our data, together with previous results, suggest that this pathogen could not be involved in the onset of the abortive phenomena in association with a chorionic villi infection. This bacterium was previously detected in endocervical swabs, in the cervix, placenta and urine of women affected by early pregnancy loss (Ahmadi et al., 2016; Sisakht et al., 2017). In the current study, the negative trend was confirmed in the corresponding PBMCs for both groups, where all samples tested negative, with the only exception being a sample from the control group. These data confirm that the majority of women enrolled in this study have no active C. trachomatis infection (Hook et al., 2004).

This study reports qualitative and quantitative PCR data on bacterial DNAs investigated in chorionic villi tissue samples and PBMCs from women affected by early pregnancy loss. Samples tested positive for $U$. parvum, $U$. urealyticum and $M$. hominis, as well as the presence of $C$. trachomatis, although in a minor percentage, enhanced our knowledge of the association between silent infections and SA. Future investigations are needed to elucidate the role of these bacteria in the SA.

\section{FUNDING}

This work was supported by the University of Ferrara, FAR grants to C. Contini, F. Vesce, M. Tognon, F. Martini (grant 2017 and 2018); and Regione Emilia Romagna-Università degli Studi di Ferrara "Ricerca finalizzata Young Investigator" to A. Graziano (grant numbers 2015).

\section{CONFLICTS OF INTEREST}

The authors declare no conflicts of interest.

\section{ORCID}

Mauro Tognon (D) http://orcid.org/0000-0001-8269-7937 


\section{REFERENCES}

Absalan, F., Ghannadi, A., Kazerooni, M., Parifar, R., Jamalzadeh, F., \& Amiri, S. (2012). Value of sperm chromatin dispersion test in couples with unexplained recurrent abortion. Journal of Assisted Reproduction and Genetics, 29, 11-14.

Adachi, K., Nielsen-Saines, K., \& Klausner, J. D. (2016). Chlamydia trachomatis infection in pregnancy: The global challenge of preventing adverse pregnancy and infant outcomes in Sub-Saharan Africa and Asia. BioMed Research International, 2016, 9315757.

Ahmadi, A., Khodabandehloo, M., Ramazanzadeh, R., Farhadifar, F., Nikkhoo, B., Soofizade, N., \& Rezaii, M. (2014). Association between Ureaplasma urealyticum endocervical infection and spontaneous abortion. Iranian Journal of Microbiology, 6, 392-397.

Ahmadi, A., Khodabandehloo, M., Ramazanzadeh, R., Farhadifar, F., Roshani, D., Ghaderi, E., \& Farhangi, N. (2016). The relationship between Chlamydia trachomatis genital infection and spontaneous abortion. Journal of Reproduction and Infertility, 17, 110-116.

Baud, D., Goy, G., Jaton, K., Osterheld, M. -C., Blumer, S., Borel, N., ... Greub, G. (2011). Role of Chlamydia trachomatis in miscarriage. Emerging Infectious Diseases, 17, 1630-1635.

Borghi, A., Caselli, E., Di Luca, D., Sebastiani, A., Perri, P., Seraceni, S., ... Virgili, A. (2013). Detection of Chlamydophila pneumoniae and human herpesvirus 8 in primary cutaneous anaplastic large-cell lymphoma: A case report. Infectious Agents and Cancer, 8, 41.

Cardenas, I., Means, R. E., Aldo, P., Koga, K., Lang, S. M., Booth, C., ... Mor, G. (2010). Viral infection of the placenta leads to fetal inflammation and sensitization to bacterial products predisposing to preterm labor. Journal of Immunology, 185, 1248-1257.

Cultrera, R., Seraceni, S., Germani, R., \& Contini, C. (2006). Molecular evidence of Ureaplasma urealyticum and Ureaplasma parvum colonization in preterm infants during respiratory distress syndrome. BMC Infectious Diseases, 6, 166.

de la Rochebrochard, E., \& Thonneau, P. (2002). Paternal age and maternal age are risk factors for miscarriage; results of a multicentre European study. Human Reproduction, 17, 1649-1656.

Donders, G. G., Van Bulck, B., Caudron, J., Londers, L., Vereecken, A., \& Spitz, B. (2000). Relationship of bacterial vaginosis and mycoplasmas to the risk of spontaneous abortion. American Journal of Obstetrics and Gynecology, 183, 431-437.

Dong, Z. W., Li, Y., Zhang, L. Y., \& Liu, R. M. (1998). Detection of Chlamydia trachomatis intrauterine infection using polymerase chain reaction on chorionic villi. International Journal of Gynaecology and Obstetrics: The Official Organ of the International Federation of Gynaecology and Obstetrics, 61, 29-32.

Farhadifar, F., Khodabandehloo, M., Ramazanzadeh, R., Rouhi, S., Ahmadi, A., Ghaderi, E., ... Rezzaii, M. (2016). Survey on association between Mycoplasma hominis endocervical infection and spontaneous abortion using polymerase chain reaction.. International Journal of Reproductive Biomedicine, 14, 181-186.

Giakoumelou, S., Wheelhouse, N., Cuschieri, K., Entrican, G., Howie, S. E. M., \& Horne, A. W. (2016). The role of infection in miscarriage. Human Reproduction Update, 22, 116-133.

Hook, C. E., Telyatnikova, N., Goodall, J. C., Braud, V. M., Carmichael, A. J., Wills, M. R., \& Gaston, J. S. H. (2004). Effects of Chlamydia trachomatis infection on the expression of natural killer (NK) cell ligands and susceptibility to NK cell lysis. Clinical and Experimental Immunology, 138, 54-60.

Kooper, A. J. A., Faas, B. H. W., Feuth, T., Creemers, J. W. T., Zondervan, H. H., Boekkooi, P. F., ... Smits, A. P. T. (2009). Detection of chromosome aneuploidies in chorionic villus samples by multiplex ligation-dependent probe amplification. Journal of Molecular Diagnostics, 11, 17-24.

Larsen, B., \& Hwang, J. (2010). Mycoplasma, Ureaplasma, and adverse pregnancy outcomes: A fresh look. Infectious Diseases in Obstetrics and Gynecology, 2010, 1-7.
Maconochie, N., Doyle, P., Prior, S., \& Simmons, R. (2007). Risk factors for first trimester miscarriage-Results from a UK-population-based casecontrol study. BJOG: An International Journal of Obstetrics and Gynaecology, 114, 170-186.

Miles, S., Rogers, K. M., Thomas, P., Soans, B., Attia, J., Abel, C., ... Hensley, M. J. (2009). A comparison of single-photon emission CT lung scintigraphy and CT pulmonary angiography for the diagnosis of pulmonary embolism. Chest, 136, 1546-1553.

Mor, G., \& Cardenas, I. (2010). The immune system in pregnancy: A unique complexity. American Journal of Reproductive Immunology, 63, 425-433.

Nigro, G., Mazzocco, M., Mattia, E., Di Renzo, G. C., Carta, G., \& Anceschi, M. M. (2011). Role of the infections in recurrent spontaneous abortion. The Journal of Maternal-Fetal \& Neonatal Medicine, 24, 983-989.

Novy, M. J., Duffy, L., Axthelm, M. K., Sadowsky, D. W., Witkin, S. S., Gravett, M. G., ... Waites, K. B. (2009). Ureaplasma parvum or Mycoplasma hominis as sole pathogens cause chorioamnionitis, preterm delivery, and fetal pneumonia in rhesus macaques. Reproductive Sciences, 16, 56-70.

Oyarzún, E., Yamamoto, M., Katoa, S., Gómez, R., Lizama b, L., \& Moenne, A. (1998). Specific detection of 16 micro-organisms in amniotic fluid by polymerase chain reaction and its correlation with preterm delivery occurrence. American Journal of Obstetrics and Gynecology, 179, 1115-1119.

Perni, S. C., Vardhana, S., Korneeva, I., Tuttle, S. L., Paraskevas, L.-R., Chasen, S. T., ... Witkin, S. S. (2004). Mycoplasma hominis and Ureaplasma urealyticum in midtrimester amniotic fluid: Association with amniotic fluid cytokine levels and pregnancy outcome. American Journal of Obstetrics and Gynecology, 191, 1382-1386.

Rasti, S., Ghasemi, F. S., Abdoli, A., Piroozmand, A., Mousavi, S. G. A., \& Fakhrie-Kashan, Z. (2016). ToRCH "co-infections" are associated with increased risk of abortion in pregnant women. Congenital Anomalies, 56, 73-78.

Robertson, J. A. (1986). Ureaplasmas of human: With emphasis upon maternal and neonatal infections. Future considerations: Basic biology. Pediatric Infectious Disease, 5, S345.

Romero, R., Miranda, J., Kusanovic, J. P., Chaiworapongsa, T., Chaemsaithong, P., Martinez, A., ... Kim, Y. M. (2015). Clinical chorioamnionitis at term I: Microbiology of the amniotic cavity using cultivation and molecular techniques. Journal of Perinatal Medicine, 43, 19-36.

Romero, R., Sirtori, M., Oyarzun, E., Avila, C., Mazor, M., Callahan, R., ... Hobbins, J. C. (1989). Infection and labor. V. Prevalence, microbiology, and clinical significance of intraamniotic infection in women with preterm labor and intact membranes. American Journal of Obstetrics and Gynecology, 161, 817-824.

Rotondo, J. C., Bononi, I., Puozzo, A., Govoni, M., Foschi, V., Lanza, G., ... Tognon, M. (2017). Merkel cell carcinomas arising in autoimmune disease affected patients treated with biologic drugs, including antiTNF. Clinical Cancer Research: An Official Journal of the American Association for Cancer Research, 23, 3929-3934.

Rotondo, J. C., Borghi, A., Selvatici, R., Magri, E., Bianchini, E., Montinari, E., ... Martini, F. (2016). Hypermethylation-induced inactivation of the IRF6 gene as a possible early event in progression of vulvar squamous cell carcinoma associated with lichen sclerosus. JAMA Dermatol, 152, 928-933.

Rotondo, J. C., Bosi, S., Bassi, C., Ferracin, M., Lanza, G., Gafà, R., ... Martini, F. (2015). Gene expression changes in progression of cervical neoplasia revealed by microarray analysis of cervical neoplastic keratinocytes. Journal of Cellular Physiology, 230, 806-812.

Rotondo, J. C., Bosi, S., Bazzan, E., Di Domenico, M., De Mattei, M., Selvatici, R., ... Martini, F. (2012). Methylenetetrahydrofolate reductase gene promoter hypermethylation in semen samples of infertile couples correlates with recurrent spontaneous abortion. Human Reproduction, 27, 3632-3638. 
Rotondo, J. C., Candian, T., Selvatici, R., Mazzoni, E., Bonaccorsi, G., Greco, P., ... Martini, F. (2017). Tracing males from different continents by genotyping JC polyomavirus in DNA from semen samples. Journal of Cellular Physiology, 232, 982-985.

Rotondo, J. C., Selvatici, R., Di Domenico, M., Marci, R., Vesce, F., Tognon, M., \& Martini, F. (2013). Methylation loss at H19 imprinted gene correlates with methylenetetrahydrofolate reductase gene promoter hypermethylation in semen samples from infertile males. Epigenetics, 8, 990-997.

Sisakht, A. J., Omidifar, N., Mohamadkhani, N., Karimpoorfard, M., Kargar, M., \& Shokripour, M. (2017). Assessing the presence of Chlamydia trachomatis genome in pregnant women with spontaneous abortion using polymerase chain reaction method in Yasuj: First report from Southwest of Iran. Journal of Education and Health Promotion, 6, 45.

Suzumori, N., \& Sugiura-Ogasawara, M. (2010). Genetic factors as a cause of miscarriage. Current Medicinal Chemistry, 17, 3431-3437.

Taylor-Robinson, D. (2017). Mollicutes in vaginal microbiology: Mycoplasma hominis, Ureaplasma urealyticum, Ureaplasma parvum and Mycoplasma genitalium. Research in Microbiology, 168, 875-881.

Yi, J., Yoon, B. H., \& Kim, E. -C. (2005). Detection and biovar discrimination of Ureaplasma urealyticum by real-time PCR. Molecular and Cellular Probes, 19, 255-260.
Yoon, B. H., Romero, R., Kim, M., Kim, E. C., Kim, T., Park, J. S., \& Jun, J. K. (2000). Clinical implications of detection of Ureaplasma urealyticum in the amniotic cavity with the polymerase chain reaction. American Journal of Obstetrics and Gynecology, 183, 1130-1137.

Yoon, B. H., Romero, R., Park, J. S., Chang, J. W., Kim, Y. A., Kim, J. C., \& Kim, K. S. (1998). Microbial invasion of the amniotic cavity with Ureaplasma urealyticum is associated with a robust host response in fetal, amniotic, and maternal compartments. American Journal of Obstetrics and Gynecology, 179, 1254-1260.

You, H., Liu, Y., Agrawal, N., Prasad, C. K., Edwards, J. L., Osborne, A. F., ... Hermonat, P. L. (2008). Multiple human papillomavirus types replicate in 3A trophoblasts. Placenta, 29, 30-38.

How to cite this article: Contini C, Rotondo JC, Magagnoli F, et al. Investigation on silent bacterial infections in specimens from pregnant women affected by spontaneous miscarriage. J Cell Physiol. 2018;1-8. https://doi.org/10.1002/jcp.26952 